\title{
Association between job satisfaction and workers' quality of life in a public maternity hospital in the far north of Brazil
}

\author{
Manuela Siraiama Marques-Duarte 1 \\ https://orcid.org/0000-0002-7373-7885 \\ Demilto Yamaguchi da Pureza 2 \\ https://orcid.org/0000-0001-8336-2178
}

\footnotetext{
1,2 Programa de Pós-graduação em Ciências da Saúde. Universidade Federal do Amapá. Rodovia Juscelino Kubistcheck de Oliveira Km 02. Macapá, Amapá, Brasil. CEP: 68.902-280. E-mail: msmd.pesquisa@gmail.com
}

\begin{abstract}
Objectives: to correlate the levels of job satisfaction (JS) and quality of life (QOL) of public maternity workers.

Methods: quantitative and correlational cross-sectional study. Sample composed of 199 state public servants, of both genders, of different age groups and professions, working at the Women's Hospital Mother Luzia (WHML), in Macapá (AP). Three questionnaires were used: Sociodemographic, Job Satisfaction S20/23 and WHOQOL-Brief. Statistical analysis was performed by Pearson correlation and analysis of variance, with statistical significance at $5 \%$.

Results: most of the sample consisted of women (84.2\%), aged between 30 and 39 years (40.7\%), with a partner (64.3\%), practicing physical activity (50.8\%). With university education, (61.8\%), income up to four minimum wages (53.3\%), worked in two or more jobs (53.7\%); and weekly workload of up to 30 hours (79.4\%). They reported job dissatisfaction (75.4\%). The average overall QOL was 65.62 ( \pm 12.45$)$. JS was associated with $Q O L$ $(p<0.001)$ and number of jobs $(p=0.019)$. QOL was associated with male gender $(p=0.022)$, income ( $p=0.004)$, ST $(p<0.001)$, physical activity $(p=0.067)$ and workload $(p=0.011)$. The correlations between JS and QOL were all significant.

Conclusions: the quality of life of WHML workers was directly and progressively associated with job satisfaction, which meant that higher levels of job satisfaction favored the quality of life.
\end{abstract}

Key words Job satisfaction, Quality of life, Occupational health

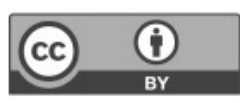




\section{Introduction}

Job satisfaction can be understood as a pleasurable emotional state resulting from the perception that the worker has about his work and how this job satisfies him or allows satisfaction of the values considered relevant to his life. This is one of the main indicators of quality of working life, since both satisfaction and dissatisfaction become influencers of work, motivating them in the case of satisfaction or discouraging them in the case of dissatisfaction. ${ }^{1}$

In Locke's theoretical perspective, work takes on a complex and interactionist character, permeating a multitude of elements, which determine global job satisfaction when satisfied and global job dissatisfaction when dissatisfied or not fully satisfied. ${ }^{2}$

Dissatisfaction at work may favor the onset of illnesses such as occupational stress, burnout and mental and behavioral disorders. These repercussions are influenced by factors such as long working hours, shortage of human and material resources, intense demand for medical care, low pay, job accumulation, exposure to suffering and death of patients. ${ }^{3}$ Maternity work, especially in the public sphere combines several of these elements, contributing to worker burnout and job dissatisfaction.

The concept of quality of life can be defined as the result of the interrelationship between various aspects of human nature, for example, the individual with himself, the individual and his community, and the individual and his work. It is a comprehensive concept that involves the perception of individuals about their positioning in life, their social and cultural context, level of independence and value systems that they establish about life goals, expectations and yearnings. ${ }^{4}$

The Women's Hospital Mother Luzia (WHML) is the public referral hospital in the state of Amapá, far north of Brazil, for medium and high complexity gynecological, obstetric and neonatal care. The Amapá State has a birth rate of 2.29 children per woman, higher than the national average, and besides, $91 \%$ of the inhabitants access health services mostly through the Unified Health System (SUS - Portuguese acronym). 5

In addition to state demand, the WHML receives a significant number of patients from other states such as Pará and Maranhão, as well as French Guiana, who have already accounted for more than $30 \%$ of the total attended at the hospital. These situations seem to contribute to the constant overcrowding of the institution and, therefore, to the precariousness of working conditions and the quality of care provided to users.

Given the high demand for health care at WHML and sometimes insufficient material and human resources, workers tend to be exposed to inadequate working conditions, which in turn may compromise their professional performance and impact on their health and quality of life. Thus, the present study aimed to correlate the levels of job satisfaction and quality of life of workers of a public maternity hospital in the far north of Brazil.

\section{Methods}

This is a cross-sectional, quantitative and correlational study conducted with health workers at the WHML, a public maternity referral center for the care of medium and high complexity in the state of Amapá. This study complied with the required ethical criteria and the recommendations of the National Research Ethics Committee, according to Opinion 2.410.107 and CAAE 78919417.7.0000. 0003.

The population consisted of health care workers from the state civil servants, officially employed in the institution, from various professional categories, of both genders, of any age group and who signed the free and informed consent term. Workers with another type of employment and those on leave or vacation were excluded. The inclusion criteria met 409 servers.

To calculate the sample, the criteria established in Barbetta ${ }^{6}$ sampling theory were followed, and the sampling error was assumed to be $5 \%$, using the equation:

$$
n=\frac{N \cdot n_{0}}{N+n_{0}} \quad \text { being } \quad n_{0}=\frac{1}{\varepsilon_{0}^{2}}
$$

Where: $N$ - is the size of the selected population; $n$ - is the sample; $\mathcal{E}$ - is the sampling error.

Thus, the estimated sample consisted of 203 participants and, at the end of the collection period, included 199 servers.

The research inventories used were: sociodemographic questionnaire; Job Satisfaction Questionnaire (JSQS20/23) for the analysis of overall job satisfaction and dimensions; and the World Health Organization Quality of Life Questionnaire, short version (WHOQOL-Brief), to assess general quality of life and domains.

The JSQ S20/23 allows the investigation of the job satisfaction of workers from different areas. This is the short version of Questionnaire S4/827 and is an efficient and convenient assessment of job satis- 
faction levels and dimensions, consisting of 23 questions divided into five factors. The short version of the instrument was validated in Brazil. ${ }^{8}$ During the process it was recommended to use the model with twenty requirements divided into three dimensions intrinsic job satisfaction (IJS), satisfaction with the physical work environment (SPWE) and satisfaction with hierarchical relationships (SHR) - since the other three items in the original Spanish questionnaire had factor loadings in more than one dimension.

The version validated for use in Brazil had satisfactory reliability, internal consistency, and validity indices. ${ }^{8}$ The instrument score is given by a Likert scale and the answers scored as very dissatisfied $=1$ point; dissatisfied $=2$ points; neither satisfied nor dissatisfied $=3$ points; satisfied $=4$ points; and very satisfied $=5$ points, with a minimum overall score of 20 and a maximum of 100 . After counting the points, the arithmetic mean and standard deviation for both overall satisfaction and dimensions are calculated using the score scale correspondence, thus determining the respondent's satisfaction level. 7 For the present study, scores less than or equal to 2.99 were considered dissatisfaction, and scores of 3.00 or more were considered as satisfaction for both general satisfaction and its dimensions.

The WHOQOL-Brief is the World Health Organization's tool for assessing the quality of life and its domains. It consists of 26 items distributed in four domains: physical, social relations, environment and psychological. The instrument scores are obtained by Likert scale, where $1=$ nothing; $2=$ little; 3 = medium; $4=$ sufficient; $5=$ a lot, with slight variations according to the wording of the question. The WHOQOL-Brief syntax recommends an inverted score for items 3, 4 and 26. The questionnaire score has no cutoff, so the closer to one hundred points, the better the quality of life. ${ }^{4}$ The instrument was properly validated in Brazil. ${ }^{9}$

Workers were invited to participate in the research after a presentation visit to the work sectors. Those who expressed interest in participating reported the most convenient time and place to answer the questionnaires. Data collection took place from February to May 2018, in the three work shifts, in the hospital itself, in a place of participant's choice (work sector or private room).

Data were systematized in a spreadsheet and a statistical analysis was performed using the Statistical Package for Social Sciences (SPSS ${ }^{\circledR}$ ) version 22.0 software. The characterization of the variables was made through mean and standard deviation for quantitative variables and absolute (n) and relative (\%) frequencies for qualitative variables. As for the inferential analysis, Pearson's correlation coefficient and variance analysis were used.

\section{Results}

The final sample comprised 199 participants, of which $82.4 \%$ were female, with a mean age of 41.8 \pm 9.6 years, with the most frequent age group between 30 and 39 years, with $40.7 \%, 64.8 \%$ lived with a partner, $50.8 \%$ reported practicing physical activity. The most frequent middle and upper-level professional categories were nursing technicians $(26.1 \%)$ and doctors $(16.6 \%)$, respectively. As for the number of jobs, $53.8 \%$ had two or more, and for $80.4 \%$ the WHML was the largest source of income, which was up to four minimum wages for the majority $(53.3 \%)$. The most frequent weekly workload was up to 30 hours $(62.3 \%)$ (Table 1).

Most workers, $75.4 \%$, had dissatisfaction (Table $1)$, with a mean of $2.53( \pm 0.73)$ for overall job satisfaction. The best-scored dimension was IJS (3.29 \pm $0.87)$, followed by SHR $(2.55 \pm 0.89)$ and the lowest scored was SPWE $(2.05 \pm 0.88)$ (Table 2$)$.

The average overall quality of life among the servers was $65.62( \pm 12.45)$. The domain with the highest score was social relations $(70.31 \pm 16.38)$ and the domain with the lowest score was the environment $(56.27 \pm 14.85)$ (Table 2).

Regression analysis indicated two factors associated with overall job satisfaction: number of jobs $(p=0.019)$ and quality of life level $(p<0.001)$ (Table $3)$. The factors that influenced the quality of life were: gender $(p=0.022)$; income $(p=0.004)$, total workload $(p=0.011)$, job satisfaction $(p<0.001)$ and physical activity ( $p=0.067)$, with proximity to statistical significance (Table 4). Correlation analysis showed a statistically significant association between the variables job satisfaction and quality of life, both for the general mean scores and scores by dimensions of each of the variables (Table 5).

\section{Discussion}

Regarding the socio-demographic profile of the participants, $82.4 \%$ were female, similar to most studies in the health area, a situation that may be related to the socio-historical characteristics of the professions in the area where there is a predominance of females. 10

The average age of the respondents was $41.8 \pm$ 9.6 years, with the predominant age range from 30 to 39 years, with $40.7 \%$ of the total. The average obtained in this study was similar to other studies on 
Table 1

\begin{tabular}{|c|c|c|}
\hline Variables & $\mathrm{N}=199$ & $\%$ \\
\hline \multicolumn{3}{|l|}{ Gender } \\
\hline Female & 164 & 82.4 \\
\hline Male & 35 & 17.6 \\
\hline \multicolumn{3}{|l|}{ Age (years) } \\
\hline Up to 29 & 15 & 7.5 \\
\hline $30-39$ & 81 & 40.7 \\
\hline $40-49$ years & 58 & 29.1 \\
\hline 50 or more years & 45 & 22.6 \\
\hline \multicolumn{3}{|l|}{$\bar{X}=41.8( \pm 9.6)$} \\
\hline \multicolumn{3}{|l|}{ Marital status } \\
\hline No companion & 70 & 24.6 \\
\hline With companion & 129 & 64.8 \\
\hline \multicolumn{3}{|l|}{ Physicalactivity } \\
\hline Not & 98 & 49.2 \\
\hline Yes & 101 & 50.8 \\
\hline \multicolumn{3}{|l|}{ Schooling } \\
\hline Medium / Technical level & 76 & 38.2 \\
\hline Higher level & 40 & 20.1 \\
\hline Higher level - Specialization & 75 & 37.7 \\
\hline Higher level - Master & 8 & 4 \\
\hline \multicolumn{3}{|l|}{ Professional category } \\
\hline Technician level & 81 & 40.7 \\
\hline Nursing Technician & 52 & 26.1 \\
\hline Laboratory Technician & 11 & 5.5 \\
\hline Pharmacy Assistant & 7 & 3.5 \\
\hline Administrative Assistant & 3 & 1.5 \\
\hline Nutrition Technician & 3 & 1.5 \\
\hline Radiology Technician & 3 & 1.5 \\
\hline Nursing Assistant & 2 & 1.0 \\
\hline University level & 118 & 59.3 \\
\hline Doctor & 33 & 16.6 \\
\hline Nurse & 26 & 13.1 \\
\hline Physiotherapist & 14 & 7.0 \\
\hline Nutritionist & 11 & 5.5 \\
\hline Pharmaceutical & 8 & 4.0 \\
\hline Speech therapist & 8 & 4.0 \\
\hline Social worker & 7 & 3.5 \\
\hline Psychologist & 7 & 3.5 \\
\hline Radiology Technologist & 2 & 1.0 \\
\hline Occupational Therapist & 2 & 1.0 \\
\hline \multicolumn{3}{|l|}{ Number of jobs } \\
\hline 1 & 92 & 46.2 \\
\hline 2 or more & 107 & 53.8 \\
\hline \multicolumn{3}{|l|}{ WHML leading source of income } \\
\hline Yes & 160 & 80.4 \\
\hline Not & 39 & 19.6 \\
\hline
\end{tabular}


Sociodemographic and occupational characteristics and work satisfaction of WHML workers, Macapá, AP, 2018.

\begin{tabular}{lcc}
\hline Variables & N=199 & $\%$ \\
\hline Income (minimum wage) & & 106 \\
Up to 4 & 55 & 53.3 \\
4 up to 6 & 18 & 27.6 \\
Over 6 up to 8 & 20 & 9.0 \\
than 8 & & 10.1 \\
$\bar{X}=5.5( \pm 2.25)$ & & 62.3 \\
Total workload & 124 & 8.5 \\
Up to 30 & 17 & 18.6 \\
31 to 50 & 37 & 10.6 \\
51 to 70 & 21 & 75.4 \\
71 or more & & 24.6 \\
Job satisfaction & 150 & 49 \\
Not & & \\
\hline
\end{tabular}

Table 2

\begin{tabular}{|c|c|c|c|}
\hline \multicolumn{2}{|c|}{ Job satisfaction } & \multicolumn{2}{|c|}{ Quality of life } \\
\hline Dimensions & $\bar{X} \pm S D$ & Domains & $\bar{X} \pm S D$ \\
\hline IJS & $3.29 \pm 0.87$ & Social relationships & $70.31 \pm 16.38$ \\
\hline SHR & $2.55 \pm 0.89$ & Psychical & $69.47 \pm 14.52$ \\
\hline SPWE & $2.05 \pm 0.88$ & Physicist & $66.44 \pm 15.38$ \\
\hline \multirow[t]{2}{*}{ Overall satisfaction } & $2.53 \pm 0.73$ & Environmental & $56.27 \pm 14.85$ \\
\hline & & Overall quality of life & $65.62 \pm 12.45$ \\
\hline
\end{tabular}

IJS = intrinsic job satisfaction; SHR = satisfaction with hierarchical relationships; SPWE = satisfaction with the physical work environment; WHML = Women's Hospital Mother Luzia. Scores obtained by Likert scales.

Table 3

Factors that influence job satisfaction, WHML, Macapá, 2018. (N = 199)., 2018.

Independent variables

Regression coefficients

$p$

\begin{tabular}{lccc} 
& \multicolumn{2}{c}{ Not adjusted $(B)$} & Adjusted $(\beta)$ \\
\hline Number of jobs & -0.17 & -0.16 & 0.019 \\
Quality of life & 0.02 & 0.36 & $<0.001$ \\
\hline
\end{tabular}

Regression model: Dependent Variable: Job satisfaction;

General

Anova: $F_{(3.194)}=13,14(p<0.001) ; R^{2}=0.411$

Excluded variables $(p>0.05)$ : gender, age, marital status, income, physical activity, professional category, total workload.

$\mathrm{RC}=$ Reference Category 
Table 4

\begin{tabular}{|c|c|c|c|c|}
\hline \multirow[t]{2}{*}{ Independent variables } & & \multicolumn{2}{|c|}{ Regression coefficients } & \multirow[t]{2}{*}{$p$} \\
\hline & & Not adjusted (B) & Adjusted $(\beta)$ & \\
\hline Gender (RC - Female) & Male & 4.89 & 0.15 & 0.022 \\
\hline Physical activity (RC - No) & Yes & 2.99 & 0.12 & 0.067 \\
\hline Income & Continuous variable & 1.06 & 0.19 & 0.004 \\
\hline Total workload & Continuous variable & -0.09 & -0.17 & 0.011 \\
\hline Overall job satisfaction & Continuous variable & 5.49 & 0.32 & $<0.001$ \\
\hline
\end{tabular}

Regression Model: Dependent Variable - Overall Quality of life

Anova: $F_{(5,195)}=10.58(p<0.001) ; R^{2}=0.465$

Excluded variables ( $p>0.05)$ : age, marital status, number of jobs, professional category.

$\mathrm{RC}=$ Reference Category.

Table 5

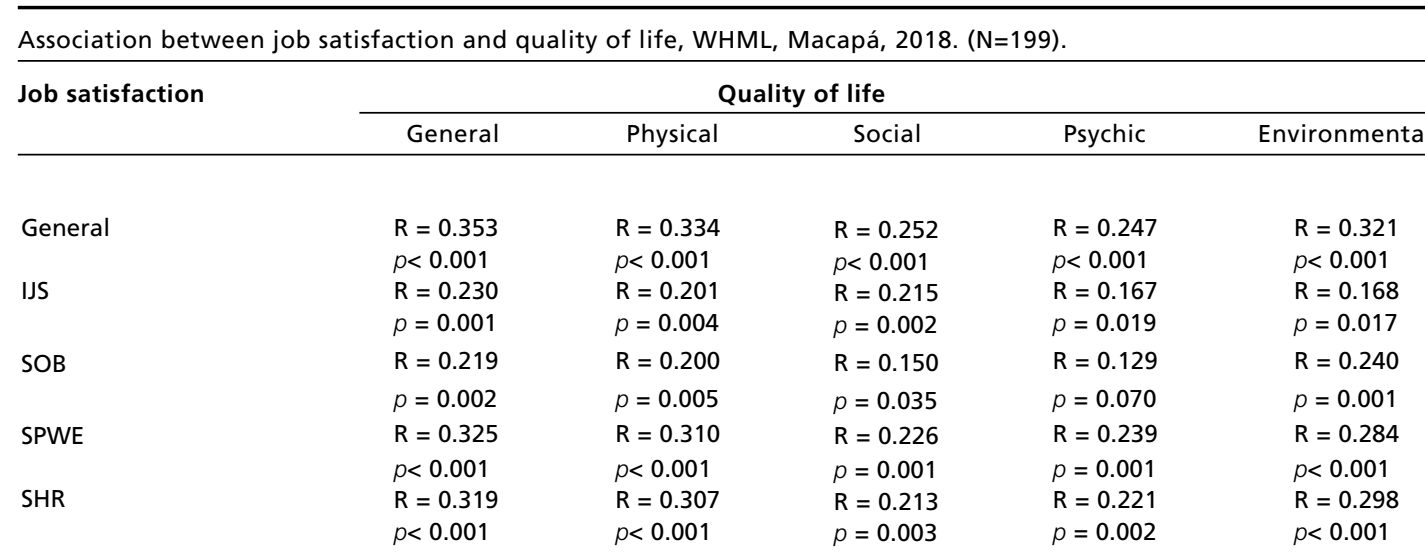

$\mathrm{R}=$ Pearson correlation coefficient, between job satisfaction and quality of life, with Likert-type scores; IJS = intrinsic job satisfaction; SOB = satisfaction with the offer of benefits; SPWE = satisfaction with the physical work environment; $\mathrm{SHR}=$ satisfaction with hierarchical relationships.

this subject. 11,12 Regarding marital status, $64.8 \%$ of workers lived with a partner, a condition frequently observed in studies involving health professionals, with similar values, ${ }^{12,13}$ or older. ${ }^{14,15}$ This result may be associated with the participants' mean age.

Regarding the regular and optional practice of physical activity, there was a balance between practitioners and non-practitioners, $50.8 \%$ and $49.2 \%$ respectively. A study on professional burnout in nurses found $65.7 \%$ of non-practitioners, a condition that contributed to burnout. 14 Failure to engage in regular physical activity can contribute to the occurrence of common mental disorders in the health team. 16 Physical activity may decrease symptoms of anxiety and depression in the nursing staff. 17

This study included several professional categories working in the WHML, which represented a differential concerning research in the area, which often involves nursing teams, 14,18 and teams composed of nursing staff and doctors. 12 The option to include different categories of performance in the hospital can contribute to a better understanding of workers' health in this environment.

In the WHML, most present middle and higherlevel categories were nursing technicians and doctors, respectively. However, it was observed that 
the number of participants by professional category was different from the number by educational level. This fact may have been due to the information on the higher level of education completed by the participants, which is the most common situation among middle-level employees in the institution.

The shift work in the hospital health area stems from the need for uninterrupted care to the hospitalized patient. However, this characteristic contributes to the frequent occurrence of multiple working hours and/or work bonds by the same worker. Among the participants in this survey, $53.4 \%$ reported having two or more jobs, while those reporting only one job totaled $46.2 \%$. Upon confirmation of more than one job, participants were instructed to consider the characteristics and perceptions only about working at the WHML, and for those with two links at the institution, it was suggested that they answer two different sets of forms, one for each work sector.

The occurrence of multiple jobs in health can be observed in research on different themes. In research on worker health at a medical specialty center, it was observed that $84 \%$ of workers had more than one formal employment relationship, which may be explained by the respondents' high dissatisfaction with the remuneration received. 13 However, the result on screen was superior to studies of a similar nature that found workers with two or more jobs, $21.9 \%, 1221.4 \%, 1117.1 \% .14$

Although most employees have more than one job, for $80.4 \%$ of participants, employment in WHML is the main source of income, whose average value was between five and six-monthly minimum wages. However, regarding the representativeness of income brackets, $53.3 \%$ of the employees reported receiving up to four monthly minimum wages. The higher average value in relation to the most frequent range, may be due to the higher salaries received by professionals of some categories that perform duty scales with additional remuneration.

When considering the average income of the servers, about 5.5 minimum wages, the values observed in this research stand out against the findings of a study with a nursing staff of a mediumsized hospital. ${ }^{19}$ However, the average income of this study was lower than that observed among nurses of a public hospital in the state of Paraná, with an average of 7.5 minimum wages. 10

Work relates to various aspects of people's lives. The interaction between the worker, his work and the context in which it operates results in a subjective and individual humanization process, which influences job satisfaction and can be understood as an indicator of worker health and well-being. 20
Insofar as it allows the analysis of the components of the work environment and organization and their relations with the subject who acts in it, work satisfaction can be understood as a positive emotional response issued by the worker in the face of the evaluation of all components of the work and himself as a productive agent. 13

Work dissatisfaction observed in this study (74.6\%) was much higher than the $6.6 \%$ dissatisfaction found among nursing workers 18 and $16.3 \%$ among intensive care physicians. ${ }^{21}$ Given the significant occurrence of dissatisfaction, it is admitted that such perception may come from a factor common to workers, such as the environmental and organizational factors of work.

In an analysis of the satisfaction of workers from Psychosocial Care Centers in Southern Brazil22 the result was $33.6 \%$ of dissatisfaction, which was associated with inadequate working conditions, especially lack of resources to perform work, an overload of tasks and the mid-level category. In the present study, only the medium level professional category, as an independent variable, presented a statistical association with job satisfaction, with a similar result.

The regression analysis between job satisfaction and its dimensions with sociodemographic and occupational variables showed two associations: the number of jobs ( $p=0.019)$, inversely; and the perception of the quality of life $(p<0.001)$, directly. The other independent variables were not associated with job satisfaction.

A study on job satisfaction of nursing professionals in public hospital showed an inverse association between job satisfaction and the number of jobs and type of labor bond of respondents. 20 In the WHML, the type of bond was homogeneous, and therefore was not one variable analyzed, however, the findings on the number of jobs corroborated with this research.

Acting in multiple health jobs tends to increase the risk of burnout, as the latter may be an organism's response to exposure to inappropriate and unhealthy work environments. Besides, we can observe the association between the dimensions of job satisfaction and the dimensions of exhaustion syndrome and some socio-occupational characteristics, such as level of education, profession, and workload. 23

The total weekly workload of WHML servers is constituted by the addition of the workload from extra shifts to the workload originally exercised by the server. Among the participants, $28.6 \%$ of the employees reported a weekly workload of 50 hours 
or more and could reach 132 hours, a condition that can contribute considerably to workwear and job dissatisfaction.

In a study on anesthesiologists' work characteristics, the most representative weekly workload was 60 to 80 hours, with $44 \%$, and reached $20.9 \%$ for those working more than 80 hours per week. 15 For the authors, this condition greatly contributed to poor sleep quality, decreased the time for physical and mental rest and increased the risk of illness and work-related accidents. Besides, overwork in hazardous environments such as the hospital can contribute to the onset or aggravation of common mental disorders. ${ }^{13}$

The environmental and organizational components of work can be considered a source of job dissatisfaction in the health area, while IJS tends to be a factor of internal accomplishment and encouragement for the worker. IJS has been positively associated with overall job satisfaction and tends to be longer-lasting, as it relates to the personal aspects of the worker and acts as a protection for mental health 21 and can contribute to the well-being and quality of life of the health worker.

Corroborating this premise, the regression analysis to determine the factors that influenced job satisfaction at WHML indicated that quality of life was directly associated with job satisfaction. Thus, the better the perceived quality of life, the greater the job satisfaction among WHML servers.

The association between job satisfaction and quality of life among the participants of this research was extremely significant since there was a positive correlation between the general constructs and their dimensions.

The general quality of life of WHML servers was from regular to good, with an average of 65.62 $( \pm 12.45)$. This score is similar to the study on the quality of life of female hospital workers in São Paulo, whose average was $64.4( \pm 12),{ }^{24}$ but the respondents had associated morbidities. Among emergency room workers, the overall average quality of life was lower $53.62( \pm 21.36) .{ }^{25}$ The authors report that some of the characteristics of hospital work, such as urgent and emergency care, rapid pace, the need of rapid decision making, critically ill patients, among others, can negatively affect quality of life.

A study on the quality of life and work of physicians of different specialties indicated an average of $62.31( \pm 19.15) .26$ According to the authors, factors such as work overload, high daily workload and unsatisfactory levels of rest and leisure may influence in the quality of life. In WHML, given the occurrence of multiple bonds $(53.8 \%)$ and the average weekly workload among workers $(43.65 \pm$ 23.8 ), such factors may be present and contribute to a lower quality of life.

Environmental working conditions can influence the perception of the quality of life, especially in the environmental domain, which had the lowest score among WHML servers, with an average of 56.3 $( \pm 14.9)$. This is a crucial domain for understanding quality of life, as it involves people's living conditions, transportation, and working environment. ${ }^{9}$

The results obtained in the WHML for this domain were similar to those of workers of a hospital in the Southeast of Brazil, whose participants had musculoskeletal symptoms, which may influence the autonomy and independence to perform daily activities, at work or home. 24

In the other direction, the most highly rated domain in the present study was social relations, with an average of $70.31( \pm 16.38)$. This domain involves personal relationships inside and outside work, family support, and social relationships in general. The analysis of this dimension enables the understanding of the social support perceived by the individual in face of life situations and challenges. 18

The social domain was also the best score even among hospital nursing workers; with an average of 76.89.18 The authors highlighted the fact that social support can positively influence the mental health of workers, as it would act as emotional and affective support in difficult situations. Among nursing workers in a hospital in São Paulo, the average was $75.0( \pm 18.6)$, despite the reported comorbidities. 24 The domain of social relations may be influenced by gender, as it has a statistical association with females. ${ }^{27}$ The female representation in the WHML was high, $82.4 \%$, a fact that may have contributed to the higher score in the social relation's domain.

Work and health are study categories that may be affected by gender. ${ }^{16}$ Female physicians had lower levels of quality of life than occupational stress and quality-of-study physicians. ${ }^{28}$ The authors related the findings to burden experienced by women regarding work activity and family responsibilities. Even if the woman is not responsible for performing the routines and tasks related to home and family, she often assumes the elaboration and conception of these processes, which overloads her.

As discussed earlier, the predominant gender among WHML workers is female, so most of these female workers may assume, at least in part, responsibility for household chores, which add up to work activities and ultimately contribute to the perception of greater psychological distress and lower levels of 
quality of life.

In an investigation regarding the occurrence of common mental disorders among higher-level health professionals from a medical and dental center, females had a higher occurrence. ${ }^{13}$ The authors pointed to domestic and family overload as a contributing factor.

Most of workers in WHML related mean income up to four minimum wages (53.3\%) and mean workload of $43.7 \pm 23.8$ hours per week. Thus, from the hypothesis mentioned by the referred authors, workers from WHML could experience moderate to good level of quality of life, which was confirmed by the results.

Correlation between workload and quality of life was observed among health professionals from three hospitals. ${ }^{29}$ According to the authors, working hours negatively influence the level of physical activity, as well as social and mental aspects. It has ratified the risk of non-communicable chronic diseases that are related to physical inactivity.

The regular practice of physical activity among the participants of this research presented a regression coefficient close to statistical significance $(p=0.067)$ because of the correlation with the quality of life, and it can be affirmed that this factor can positively influence their quality of life. The level of physical activity of nursing workers in a public hospital had a positive statistical association with a lower perception of low back pain, lower pain intensity and functional disability. 30 Considering the intense demand for work in a hospital environment, better physical conditions may contribute to minimizing the counterproductive effects of exposure to high physical demands on the workplace.

\section{References}

1. Meza AHR, Kasano JPM, Crespo HG. Satisfacción labora enelservicio de rayos $\mathrm{x}$ de una institución privada de salud de Lima, Nivel III-2, 2015. Horiz Med. 2015; 15 (3): 20-5.

2. Klein LL, Lemos RB, Pereira BAD, Beltrame G. Qualidade de vida no serviço público: uma avaliação em uma instituição de ensino superior. REAd. Rev Eletrôn Adm. 2017; 23: 317-44.

3. Silva VR, Velasque LS, Tonini T. Satisfação profissional de uma equipe de enfermagem oncológica. Rev Bras Enferm. 2017; 70 (5): 988-95.

4. The WhoqolGroup. The World Health Organization quality of life assessment (WHOQOL): position paper from the World Health Organization. Soc Sci Med. 1995; 10:1403-9.

5. IBGE (Instituto Brasileiro de Geografia e Estatística) Panorama populacional [online]. Rio de Janeiro, Brasil; 2017. [acesso 30 mai 2019]. Disponível em:
The results presented denote the complexity of the relationship between the worker, work and the environment, and corroborate similar research. The divergent findings could be understood from the analysis of the peculiarities of the studied population and the research environment. It is noteworthy that the analysis of a single hospital may limit the comparison with other work contexts and the crosssectional character of the study does not allow the establishment of cause and effect relationships between the analyzed variables.

Most of the WHML servers had job dissatisfaction and regular to good level for quality of life. Job satisfaction was associated with several jobs and quality of life. Quality of life was associated with gender, physical activity, income, workload, and job satisfaction. Job satisfaction and quality of life correlated both in the general aspects and in the dimensions of each variable. The need to improve both the environmental and organizational aspects of work at the institution is ratified, to promote job satisfaction and improve the quality of life of workers.

\section{Authors' contributions}

Marques-Duarte MS and Pureza DY participated in conception and design of research, analysis and interpretation of data and writing and review of the manuscript. Statistical analysis was performed by Marques-Duarte MS. All authors approved the final version of manuscript.

https://cidades.ibge.gov.br/brasil/ap/panorama

6. Barbetta PA. Estatística aplicada às Ciências Sociais. 5 ed. Santa Catarina: Ed. UFSC; 2002.

7. Meliá JL, PeiróJM,Calatayud C. El cuestionario general de satisfacción en organizaciones laborales: estudios factoriales, fiabilidad y validez. Millars, 1986; XI: 43-77.

8. Carlotto MS, Câmara SG. Propriedades psicométricas do Questionário de Satisfação no Trabalho (S20/23). PsicoUSF [online]. 2008; 13(2): 203-10.

9. Fleck MPA, Louzada S, Xavier M, Chachamovich E, Vieira G, Santos L, Pinzon V. Aplicação da versão em português do instrumento abreviado de avaliação da qualidade de vida "WHOQOL-BREF”. Rev Saúde Pública. 2000; 34 (2):17883.

10. Scholze A, Martins J, Grandi AL, Galdino MJ, Robazzi ML. Uso de substâncias psicoativas entre trabalhadores da 
enfermagem. Rev Port Enferm Saúde Mental. 2017; 18: 23 30 .

11. Santos EC, Andrade RD, Lopes SGR, Valgas C. Prevalence of músculo skeletal pain in nursing Professional sworking in orthopedic setting. Rev Dor. 2017; 18 (4): 298-306.

12. Ribeiro RP, Marziale MHP, Martins JT, Galdino MJQ, Ribeiro PHV. Estresse ocupacional entre trabalhadores de saúde de um hospital universitário. Rev Gaúch Enferm. 2018; 39: e65127.

13. Marcelino Filho A, Araújo TM. Estresse ocupacional e saúde mental dos profissionais do centro de especialidades médicas de Aracaju. Trab Educ Saúde. 2015; 13 (1): 177 99.

14. Vidotti V, Ribeiro RP, Galdino MJQ, Martins JT. Burnout Syndrome and shift work among the nursing staff. Rev Latinoam Enferm. 2018; 26: e3022.

15. Magalhães E, Oliveira ACMS, Govêia CS, Ladeira LCA, Queiroz DM, Vieira CV. Prevalência de síndrome de burnout entre os anestesiologistas do Distrito Federal. Rev Bras Anestesiol. 2015; 65 (2): 104-10.

16. Lua I, Almeida MMG, Araújo TM, Soares JFS, Santos KOB. Autoavaliação negativa da saúde em trabalhadoras de enfermagem da atenção básica. Trab Educ Saúde. 2018; 16 (3): 1301-19.

17. Freitas AR, Carneseca EC, Paiva CE, Paiva BS. Impactof a physicalactivityprogramontheanxiety, depression, occupational stress and burnout syndrome of nursing professionals. Rev Latinoam Enferm. 2014; 22 (2): 332-6.

18. Souza VS, Silva DS, Lima LV, Teston EF, Benedetti GMS, Costa MAR, Mendonça RR. Qualidade de vida dos profissionais de enfermagem atuantes em setores críticos. Rev Cuid. 2018; 9 (2): 2177-86

19. Duarte ACM, Lemos AC, Alcântara MA. Fatores de risco para absenteísmo de curta duração em um hospital de médio porte. Cad Saúde Colet. 2017; 25 (4): 405-13.

20. Wisniewski D, Silva ES, Évora YDM, Matsuda LM. Satisfação profissional da equipe de enfermagem $\mathrm{x}$ condições e relações de trabalho: estudo relacional. Texto Contexto Enferm. 2015; 24(3): 850-8.
21. Nassar Júnior AP, Azevedo LCP. Fatores associados à satisfação profissional e pessoal em intensivistas adultos brasileiros. Rev Bras Ter Intensiva. 2016; 28(2): 107-13.

22. Lapischies SRC, Jardim VMR, Kantorski LP. Fatores associados à satisfação no trabalho em Centros de Atenção Psicossocial. Rev Latinoam Enferm. 2014; 22 (6): 950-8.

23. Contreras-Torres F, Espinal-G L, Pachón-E AM, GonzálezR J.Burnout, liderazgo y satisfacción laboral em El personalasistencial de un hospital de tercernivelen Bogotá. Divers Perspect Psicol. 2013; 9 (1): 65-80.

24. Rodrigues MM, Fernandes RAQ. Calidadde vida y morbilidad referida a mujeres productivamente activas. Enferm Glob. 2017; 46: 246-57.

25. Silva RF, Silva SF, Barbosa TC, Maciel ES, Quaresma FRP. Nível de percepção de estresse e qualidade de vida entre os técnicos de enfermagem das unidades de pronto atendimento de Palmas - TO. Rev Bras Ciênc Saúde. 2018; 22 (3): 261-6.

26. Arenson-Pandikow MH, Oliveira LT, Bortolozzo SP, Schuch TF. Perception of Quality of Life among Anesthesiologists and Non-Anesthesiologists. Rev Bras Anestesiol. 2012; 62 (1): 48-55.

27. Nascimento IL, Duarte LCB, Moraes TD. Saúde dos psicólogos em Centros de Referência de Assistência Social. Rev Psicol Organ Trab. 2018; 18 (2): 373-80.

28. Andrade GP, Dantas RAA. Transtornos mentais e do comportamento relacionados ao trabalho em médicos anestesiologistas. Rev Bras Anestesiol. 2015; 65 (6): 50410 .

29. Freire CB, Dias RF, Schwingel PA, França EET, Andrade FMD, Costa EC, Correia Junior MAV. Qualidade de vida e atividade física em profissionais de terapia intensiva do sub médio São Francisco. Rev Bras Enferm. 2015; 68 (1): 2631 .

30. Massuda KC, Muzili NA, Lima DF, Taciro C, Oliveira Júnior AS, Martinez PF. Incidence of low back pain according to physical activity level in hospital workers. Rev Dor. 2017; 18 (1): 8-11.

\section{Received on March 12, 2019}

Final version presented on June 19, 2019

Approved on July 3, 2019 